\title{
10 Fitting informed consent onto an Islamic moral landscape and within Muslim contexts ${ }^{1}$
}

\author{
Aasim I. Padela
}

\section{Introduction}

Informed consent is a central feature of contemporary medical practice and healthcare research. Scholars have spilled much ink discussing its theoretical foundations, and healthcare professionals have convened many meetings delineating the processes of obtaining informed consent. A casual observer of these discourses may thereby assume that there is no new theoretical ground to break and that informed consent processes are universally practised and globally identical. That observer may be surprised to find that state actors such as the European Union are actively funding research on the ethics and practice of informed consent and that pharmaceutical companies such as GlaxoSmithKline and bioethics institutes such as the UNESCO Chair in Bioethics and Human Rights are actively mapping out religious and cultural dimensions of informed consent. Indeed, there remains much to discover about fulfilling the ideals and meeting the moral ends, of informed consent. This knowledge and research gap is exemplified by scant research at the intersection of the Islamic tradition and informed consent.

Where there is literature, it broadly speaks to the structural, legal and regulatory aspects of informed consent in Muslim countries and thereby bypasses in-depth analyses from within Islamic moral frameworks. ${ }^{2}$ Similarly, there are few ethnographic and social scientific studies of the lived experiences of Muslims with informed consent processes and little data on whether such practices met their ethical goals within Muslim healthcare environments. ${ }^{3} \mathrm{~A}$ few scholars have begun to analyse how research ethics is viewed by Islamic jurists ${ }^{4}$ and aligns with scriptural values, ${ }^{5}$ and this paper aims to build upon these investigations by laying the groundwork for deeper inquiry in theological ethics.

This commentary will consider how the bioethical construct of informed consent fits within an Islamic moral universe. More specifically, I will describe theological concepts that can provide homeomorphic equivalents

DOI: $10.4324 / 9781003213215-13$ 
for elements of informed consent theory. ${ }^{6}$ After this theoretical exposition, I will describe features of Muslim cultures that suggest informed consent procedures and processes need to be re-imagined and culturally adapted. Taking these features into account requires adjustments that will make informed consent processes appear different in Muslim contexts, yet arguably, the adjusted processes will achieve similar ethical ends.

\section{A conception of informed consent}

Before diving into Muslim moral contexts, I would like to provide a brief account of informed consent. I readily acknowledge there are multiple origins stories to informed consent and that informed consent practices continue to evolve. I also admit that some aspects of my representation are debatable. However, when analysing my argument, the reader will find this section to be a helpful reference point.

Informed consent is an ethical construct that grows out of the principle of respect for autonomy. ${ }^{7}$ The notion of respecting autonomy, in turn, emerges from the view that an essential characteristic of the human person is his/ her capacity and ability to make autonomous choices. ${ }^{8}$ In this way, respect for autonomy is closely related to respect for persons. This integral human capacity for deliberate choice begets moral duties; one should not infringe upon another's ability to make autonomous choices. Instead, one should facilitate such choice-making in so far as possible. The theoretical roots of informed consent attach themselves to these foundations and are implemented through acts that facilitate the patient's self-regulating decisions. Informed consent doctrine and practice thus seek to maximize the pursuit of self-interest and individual self-regulation. ${ }^{9}$ When surrogate decisionmakers are involved, the practices are someone altered but still adhere to the same ethos. ${ }^{10}$ Notably, the locus of moral concern is the individual, and as they become a right-bearer and all other members of society become morally obligated to not infringe upon those rights.

In a Western context, informed consent is established through regulations and laws that penalize healthcare systems for infringements, and standardized forms assist in seeing the informed consent process through medical care and research. Obviously, to make informed choices, an individual (or a surrogate decision-maker) must be able to understand and process the risks and benefits of the procedure or therapy, thereby meeting the ethical ends of informed consent, that is, autonomous decisions made out of self-interest requires health literacy. Furthermore, theory and practice assume rational actors. Should patients be unable to process the information required to make informed choices, be it due to cognitive deficiencies, acuity of illness or some other reason, then the healthcare team and surrogate 


\section{Aasim I. Padela}

decision-makers are morally charged with the duty to protect the patient from the harms of therapy and/or research in so far as possible. ${ }^{11}$

In its ideal form, informed consent theory and practice envision a patientdoctor dyad with reciprocal moral duties and obligations. The patient's ability to make informed decisions needs to be maximized because decisionmaking is core to being a human person, and the physician is ethically bound to do so and undertakes the responsibility to provide that biomedical data needed to make decisions. This provision of information attends to the "informed" portion of informed consent. To assure consent, the physician attempts to assess whether the patient is being coerced by others to make a certain choice by others. He works with the patient to marginalize such influences if any.

Furthermore, risks and benefits are discussed openly and transparently so that the patient can weigh them, and discussions about a patient's particular values and life goals take place to assess whether the specific choice helps meet them. In this way, the physician acts under Emanuel and Emanuel's interpretative and/or deliberative model for the doctor-patient relationship $^{12}$ and informed and voluntarily given consent is enabled. In a structured process, informed consent requires that clinicians (or researchers) provide patients (or research subjects) with sufficient information regarding the medical procedures, potential risks, benefits and alternatives (no matter how remote) so that the individual understands this information and can make a voluntary decision to take the treatment (or enrol in the research study). It further requires physicians (or researchers) to do so in a way that is understandable to the patient (or surrogate decision-makers). Next, informed processing and voluntariness on the part of the patient/ research subject (or surrogate) are accessed, and if satisfactory, then consent is secured and the procedure authorized. As noted earlier, this idealized form of a two-person dyad of a patient and a clinician (or a potential researcher subject and a researcher) often extends to surrogate decisionmakers who act on behalf of the patient. Additionally, it can extend to other healthcare team members, such as collaborating physicians and researchers, and encompass family members and important others who are essential to the patient's decision-making process.

As a leading scholar of medical ethics, Mark Siegler argues that moral certitude in the patient-doctor relationship emerges via negotiation between respective worldviews and values. ${ }^{13}$ This negotiation results in a "physicianpatient accommodation model ... in which the moral and technical arrangements of a medical encounter are determined mutually, voluntarily, and autonomously" 14 and yields a wilfully chosen, respectful and therapeutic relationship. Informed consent processes are also subject to negotiation whereby patients and doctors accommodate each other's needs and values. 
In other words, patients and doctors can negotiate how the process is carried out, who is involved, what sort of information is shared and variations can be ethically justified so long as the dyad is satisfied with the end result of the negotiation.

\section{Islamic moral theology ${ }^{15}$ and notions of informed consent}

Before venturing into Islamic thought and Muslim practices, several provisos are needed: Islamic morality is pluralistic and Muslim practices are diverse. In addition to their being two dominant sects within Islam, Sunni and Shia, each sect has multiple legal schools and orthodox creedal systems. Thus, finding a singular view on any specific matter of theology or law is challenging. Indeed, moral pluralism is an orthopraxic feature of Islamic thought and enshrined within moral and legal theory.

Additionally, as with any religious tradition, adherents live out their tenets variably. As religious beliefs inform social norms and Muslims turn Islam into a lived tradition, an immense diversity of expression is observed. One need only look to how religious dictates of modesty inform diversity in dress codes and forms of social interaction across the Muslim world to see how different people interpret how to live a religious life. This diversity is increased further when one considers Muslims whose identities are less strongly formed by religious teachings as a Muslim society's norms and practices are constituted by all inhabitants, not simply the most religious amongst them. On top of that, forms of government and state regulations also differ widely across the Muslim world, making chances for uniformity in law and ethics more remote.

On the other hand, pluralism and diversity do not equate with ethical relativism or moral anarchy. Indeed, there must be shared ideas, norms and teaching for there to be something called "Islam." In what follows, I will draw upon shared theological notions and moral teachings to point out homeomorphic equivalencies for informed consent theory within the tradition. Following that, I will describe some cultural features that may require adaptations from following Western informed consent practices to meet the ethical ends of informed consent in the Muslim world.

The notion of moral liability, takliff, provides a theological building block for a Muslim version of informed consent theory. The term symbolizes standing before God in judgement and connotes being morally responsible to God for one's actions. A morally liable person is called a mukallaf, and mukallaf status signifies that an individual has the requisite cognitive ability to recognize God, evaluate the merits and harms of actions and act wilfully out of self-interest. Therefore, taklif $f$ is linked to the maturity of intellect ( $a q l) .{ }^{16}$ The minimal intellectual capacity needed to be judged mukallaf is 
the ability to distinguish between beneficial from harmful actions (this state is termed tamy $\bar{\imath} z$ ) while having the maximal faculty leads to the adoption of righteous character (rushd).

Closely related to mukallaf is the construct of ahliyyah, legal capacity. ${ }^{17}$ Legal capacity is of two types: ahliyyah al-wujub and ahliyyah al-'ada. Aaliyah al-wujūb is the ability of a human being to acquire rights and obligations, while ahliyyah al- 'ada is the capacity for execution and performance of duties. This latter capacity is further subdivided into three categories: the capacities related to (i) criminal liability, (ii) civil/financial liability and (iii) liability for acts of ritual worship. ${ }^{18}$ While mental/intellectual maturity is a precondition for takliff (and ahliyyah al- 'ada), because mental faculty has gradations, one can be morally culpable for some acts but not others.

The linkage of mukallaf status to the intellectual capacity to distinguish harms and benefits and an ability to execute wilful actions is analogous to the theoretical foundations of informed consent. A person cannot engage in an informed consent process if they do not (i) have the cognitive resources to assess risks and benefits of choosing or are (ii) not free to choose. Being morally accountable for an action in Islam similarly demands that individuals evaluate their options and choose autonomously. Likewise, both informed consent and Islamic law require information to be presented so that a moral choice can be made; the former requiring the biomedical risks, benefits and purposes, and the latter data about the Islamic ethico-legal status of each of the proposed choices. Moreover, just like in informed consent theory, should individuals have diminished mental abilities such that they cannot work through the benefits and harms of choices, surrogate decisionmakers come to bear the moral duties of protection. It is important to note that mukallaf status is reserved for Muslims within Islamic law, and thus children and non-Muslims are considered to have mukallaf potential. The reason for this is that in the religious sense, children are considered to not be morally liable for actions prior to having reached the level of tamyizz. Their legal guardians, however, can be liable to provide recompense in this world for harms they commit, for example, paying for stolen items or property damage. Non-Muslims, on the other hand, are obviously not accountable to Islamic law, for they have not chosen Islam as the source of their moral commitments.

Moving from a theoretical space to a more practical one, it appears that Islamic law would support policies and structures that help adults with sufficient intellectual capacity make autonomous choices about medical care and research. Mukallaf status appears to provide a homeomorphic equivalency between Islamic thought and informed consent theory such that the prerequisites for moral liability in one system turn out to be the same prerequisites for decision-making in the other. By noting a homeomorphic 
equivalency, ${ }^{19} \mathrm{I}$ am not suggesting that the meaning or the function of taklif in the Islamic moral universe shares meaning or function with informed consent procedures in any way. Indeed, they operate not only in different cultural systems; they are constructs that operate at different registers with the former being a theological construct that is reflected into moral law while the latter is an ethical construct reflected within medical practices. Yet, the equivalence is helpful for bridging the values of Islam and contemporary biomedicine.

Another Islamic bioethical argument can be made to support informed consent. According to Islam, every action has moral significance and can bring about reward or retribution in the hereafter. An action that pleases God will be generally rewarded and that which displeases Him will generally be punished. Insights into God's approval or disapproval are found within the Quranic texts and the Prophet's practices. Islamic jurists thus look to these scriptural sources to determine the moral status of actions and place actions into five (or seven) categories from prohibited to obligatory and then map out the moral duties corresponding to each category. ${ }^{20}$ For example, a Muslim can be obligated to perform an act, for example, ritual prayer as well as not to perform an act, for example, drinking wine, and sin is carried for shortcomings in either non-performance or performance based on which category the act falls into. Contextual considerations and contingencies are accounted for by allowing exemptions from the normative prohibitions and specifying general rules to individual cases. In light of this, it is important to recognize that seeking medical treatment and participating in research are actions that have Islamic moral significance. Both are considered to be permitted actions but generally non-obligatory, that is, no sin for non-performance. ${ }^{21}$ However, at least in the case of seeking healthcare, the moral status of permission can be changed into a moral obligation to pursue treatment when a particular treatment is deemed certainly life-saving or when disability or contagion ensues because of non-treatment. ${ }^{22}$ A religious valuation thus depends upon a biomedical assessment of risks, benefits and harms. In other words, to properly assess the moral significance of seeking healthcare (or participating in research), biomedical data regarding the risks, benefits and harms of both non-treatment and potential treatments are necessary.

Hence, religious authorities, patients and surrogate decision-makers all require accurate biomedical data to make moral assessments within Islamic law. Recall that informed consent is built upon the principle of respecting an individual's autonomous decisions that are made voluntarily and also involves evaluating the risks and benefits of various choices. In an Islamic context, every decision has moral significance. For patients (and surrogates) to properly consider both the worldly and afterlife ramifications 


\section{2}

of seeking healthcare or participating in medical research, accurate information must be conveyed so that the moral agent can process it and make choices without coercion since the individual is morally culpable (to God) for the decisions they make. Hence, informed consent processes aid individuals in living an Islamically moral life.

In closing, Islamic moral theology appears to support informed consent theory and practice. To rightly order one's life towards God's pleasure, that is, act in accordance to Islamic ethics and law, one needs information about biomedical benefits, risks and harms attributable to each choice, one must also have the requisite mental abilities to reason through this data and ultimately be able to make a voluntary choice. Consequently, the biomedical information must be made available in an understandable form, and structures and processes need to be put into place to minimize coercion and undue influence. These ideas grow out of the construct of taklif $f$ and the human relationship to God rather than ideas about respecting autonomy or reducing infringements upon humankind's natural rights. One could argue that within an Islamic moral universe, the principle of respect for persons is operative and connects takli f to medical ethics. Certainly, when persons are viewed primarily as moral agents standing before God and the human community as their helpers, communal moral duties are delineated to facilitate individuals being better moral agents. As Sachedina states, Islam legitimizes "individual autonomy within its religiously based collective order by leaving an individual free to negotiate his/her spiritual destiny, while requiring $\mathrm{him} / \mathrm{her}$ to abide by a communal order that involve[s] . . . a regime of rights and responsibilities" 23 based in Islamic law. Consequently, the individual's exercise of autonomy is somewhat constrained because a communal order of public adherence to Islamic values is privileged. At the same time, the community, and particularly state authorities, become morally responsible for helping its members make righteous choices by providing information and enacting policies and laws that help foster a society that adheres to Islam.

\section{Muslim cultures and informed consent}

As medicine has globalized, so has bioethics. Just as medical technology and curricula are patterned after Western academies, bioethics teaching around the world also draws upon ethical principles and moral frameworks first worked out in the "West." ${ }^{24}$ It should come as no surprise then that the four-principle Georgetown model of medical ethics is widely taught in Muslim lands and that research and medical practice guidelines in these countries are borrowed from American and European institutions. While there has been increased attention given to formulating medical ethics 
guidelines based on indigenous Muslim cultural values or based on Islamic law, these efforts are in their infancy and not as yet widespread. ${ }^{25}$ Given the scant literature available on informed consent practices in Muslim contexts, these trends suggest that informed consent processes and structures likely mimic implementation models within the United States and Europe. In what follows, I will draw attention to a couple of features of Muslim culture that problematize such consent processes and thereby necessitate revising these procedures to suit Muslim sensibilities and culture.

The first feature that must be considered is that Muslim societies operate out of a communitarian ethos and shared decision-making processes. Many scholars have pointed out that within Muslim societies, the patient-doctor dyad is often not the only locus of decision-making. ${ }^{26}$ Instead, an individual in many Muslim societies is better conceived of as a person that "is wedded to social bonds that are inextricable, and [that] these bonds are a vital source of decision-making." ${ }^{27}$ People trust their relatives and community members and value interdependence. Therefore, limiting decision-making within person-centric rights can deny the value attached to such relationships. ${ }^{28}$ Moreover, as foreshadowed earlier, Islamic law defines rights that an individual has upon their community and relatives. For many Muslims, these need to be accounted for when making medical decisions. ${ }^{29}$ However, widening the circle beyond the patient-doctor dyad poses practical and ethical challenges for informed consent processes; how does one know who should be involved and where decisional authority resides? How does one distinguish coercion from acceptable influence by family members and important others? When would "forcing" a patient to act out of self-interest be ethically objectionable? Ethicists have tried to solve these problems through relational and second-order autonomy frameworks, but these fixes appear not to address the issues at hand fully. ${ }^{30}$ My colleagues and I have argued elsewhere that, at least theoretically, a culturally tailored version of the principle of respect for persons may offer an alternative ethical guide for clinicians attending to such issues but how such a principle would lead to adaptations in informed consent procedures remains to be worked out. ${ }^{31}$

A second feature of Muslim contexts that needs to be considered is that the culture of communication within many Muslim societies is high context. According to Geert Hofstede, an expert in cross-cultural issues in business, a high-context communication culture is "one in which little has to be said or written because most of the information is either in the physical environment or supposed to be known by the persons involved ... this type of communication is frequent in collectivist cultures." 32 In such cultures, individuals do not expect or desire a great deal of explicit information. Instead, too much information can leave individuals feeling uninformed and can even generate feelings of distrust. By contrast, individuals within 
low-context cultures rely on mounds of explicit information in written and oral communication and, without such information, are distrustful. In Hofstede's analyses, Arab countries were the most high-context and the United States the most low-context. As Drs. Pablo Rodriguez del Pozo and Joseph Fins, cross-cultural bioethics experts, point out that the doctrine of informed consent is vague on what constitutes adequate information and reasonable disclosure for therapeutic or research purposes. ${ }^{33}$ Given that people from high- and low-context societies expect different quanta of information, it appears that what constitutes adequate information might vary from context to context. Indeed, providing too much information in one context can lead patients to distrust clinicians, while too little information leads to the same consequence in another context; the Goldilocks scenario thus arises. As del Pozo and Fins argue, Western standards and structures for informed consent where the doctor shares detailed biomedical data with the patient do not appear to work well in Qatar (an Arab Muslim country). ${ }^{34}$ Expert physicians in that society often use family members and nonverbal clues to deliver necessary medical information and effect informed consent. They argue that there "are no objective standards to define the proper mix of verbal and contextual channels to deliver [medical] information, American standards cannot be extrapolated." ${ }^{35}$ Allying themselves with Siegler's view on patient-doctor accommodation, they contend that patients and doctors have to construct the moral norm socially and that the notion of selfdetermination within informed consent doctrine is culturally mediated. ${ }^{36}$

A third feature of Muslim societies that needs to be considered when implementing informed consent processes is how to ground ethics regulations within Islamic law. ${ }^{37}$ For example, Saudi laws on research ethics make repeated references to the Shariah as a source of ethical guidance to garner professional support for the statutes. ${ }^{38}$ Fogarty-funded research ethics training programs in Jordan similarly seek to support the teaching of the Belmont report by citing Quranic verses that appear to support its principles. ${ }^{39}$ Whether or not ethical policies and regulations are built up from the first principles of Islamic law or are based on traditional hermeneutical approaches to scripture does not appear to matter. Rather statements that note that these cohere with Islam are used to legitimize ethical regulations. Indeed, some researchers have pointed out the weak connections between Islamic moral theology and such guidelines ${ }^{40}$ Irrespective of this, the need to, at least rhetorically, attach ethical guidance to Islamic law remains true. ${ }^{41}$ Public and professional acceptance depends on such linkages, and ethicists and clinicians seeking to adapt informed consent doctrine and practices need to recognize the thirst for Islamic legitimacy. Research into conceptual analogues and homeomorphic equivalencies between Islamic theology, law and ethics and secular bioethics principles and values will 
prove fruitful in identifying ways to bridge Islam and contemporary biomedicine authentically.

\section{Conclusion}

In this essay, I have outlined how Islamic moral theology appears to support aspects of informed consent doctrine, although the ethical grounding comes from the theological construct of moral liability in front of God, and not from the principle of respect for autonomy. I have also described several features of Muslim culture, namely, its communitarian ethos, high-context communication norms, and need for ethical guidelines to be religiously legitimated, that require amending "western" processes and structures of informed consent for use in Muslim contexts. As the global bioethics community culturally translates and religiously adapts informed consent for implementation in Muslim contexts, informed consent processes may look and feel different in Muslim societies but may serve the same ethical ends.

\section{Notes}

1 A version of this paper has been published in as A.I. Padela, "Reflecting and Adapting Informed Consent to fit within an Islamic Moral Landscape and in Muslim Contexts," Studia Bioethica 11, no. 2 (2018): 31-39. The paper was also presented, in partial form, at the 6th International Bioethics, Multiculturalism and Religion workshop: Perspectives on Informed Consent. Sponsored by the UNESCO Chair in Bioethics and Human Rights in Rome. Regina Apostolorum University, Rome, Italy in March 2018.

2 Ghiath Alahmad, Mohammad Al-Jumah, and Kris Dierickx, "Review of National Research Ethics Regulations and Guidelines in Middle Eastern Arab Countries," BMC Medical Ethics 13, no. 1 (2012); Hany Sleem, Samer S. El-Kamary, and Henry J. Silverman, "Identifying Structures, Processes, Resources and Needs of Research Ethics Committees in Egypt," BMC Medical Ethics 11, no. 1 (2010); Mohammad Abdur Rab, et al., "Ethical Practices for Health Research in the Eastern Mediterranean Region of the World Health Organization: A Retrospective Data Analysis," PLoS One 3, no. 5 (2008).

3 Ghiath Alahmad, Mohammed Al Jumah, and Kris Dierickx, "Confidentiality, Informed Consent, and Children's Participation in Research Involving Stored Tissue Samples: Interviews with Medical Professionals from the Middle East," Narrative Inquiry in Bioethics 5, no. 1 (2015).

4 Ghiath Alahmad and Kris Dierickx, "What Do Islamic Institutional Fatwas Say about Medical and Research Confidentiality and Breach of Confidentiality?," Developing World Bioethics 12, no. 2 (2012).

5 Ghiath Alahmad and Kris Dierickx, "Pediatric Research Ethics: Islamic Perspectives," (2015); Hossam E. Fadel, "Ethics of Clinical Research: An Islamic Perspective," Journal of the Islamic Medical Association of North America 42, no. 2 (2010). 
6 Raimundo Panikkar, The Intrareligious Dialogue (New York: Paulist Press, 1999).

7 Marsha Garrison and Carl Schneider, The Law of Bioethics: Individual Autonomy and Social Regulation, 2nd ed., American Casebook Series (St. Paul, MN: Thomson/West, 2009); Carl Schneider, The Practice of Autonomy: Patients, Doctors, and Medical Decisions (New York: Oxford Unviersity Press, 1998); Tom L. Beauchamp and James F. Childress, "Moral Principles: Respect for Autonomy," in Principles of Biomedical Ethics (New York: Oxford University Press, 2009); James F. Childress, "The Place of Autonomy in Bioethics," The Hastings Center Report 20, no. 1 (1990); Tom L. Beauchamp and James F. Childress, Principles of Biomedical Ethics (Oxford, USA: Oxford University Press, 2001).

8 Schneider, The Practice of Autonomy: Patients, Doctors, and Medical Decisions.

9 Beauchamp and Childress, "Moral Principles: Respect for Autonomy."

10 Childress, "The Place of Autonomy in Bioethics."

11 The Belmont Report: Ethical Principles and Guidelines for the Protection of Human Subjects of Research, The National Commission for the Protection of Human Subjects of Biomedical and Behavioral Research (1979), http://ohsr. od.nih.gov/guidelines/belmont.html; Larry R. Churchill, "Toward a More Robust Autonomy: Revising the Belmont Report," in Belmont Revisited: Ethical Principles for Research with Human Subjects, ed. James F. Childress, Eric M. Meslin, and Harold T. Shapiro (Washington, DC: Georgetown University Press, 2005).

12 E.J. Emanuel and L.L. Emanuel, "Four Models of the Physician-Patient Relationship," Journal of the American Medical Association 267, no. 16 (1992).

13 Mark Siegler, "Searching for Moral Certainty in Medicine: A Proposal for a New Model of the Doctor-Patient Encounter," Bulletin of the New York Academy of Medicine 57, no. 1 (1981); Mark Siegler, "The Physician Patient Accommodation," Archives of Internal Medicine 142, no. 10 (1972).

14 Siegler, "Searching for Moral Certainty in Medicine."

15 I adopt Prof. Mohamed Fadel's usage of the English term moral theology to refer to the Islamic science of ușül al-fiqh. See M. Fadel, "The True, the Good and the Reasonable: The Theological and Ethical Roots of Public Reason in Islamic Law," Canadian Journal of Law and Jurisprudence 21, no. 1 (2008).

16 Imran Ahsan Khan Nyazee, Islamic Jurisprudence: Usul al-Fiqh (Islamabad: Islamic Research Institute, 2000); Mohammad Hashim Kamali, Principles of Islamic Jurisprudence (Cambridge: Islamic Texts Society, 2003).

17 Oussama Arabi, "Capacity, Legal," in Encyclopedia of Islam:-Three, 3rd ed., ed. Kate Fleet, et al., (Leiden, Netherlands: Brill Online, 2013); Nyazee, Islamic Jurisprudence.

18 Nyazee, Islamic Jurisprudence.

19 Panikkar, The Intrareligious Dialogue.

20 Nyazee, Islamic Jurisprudence; Kamali, Principles of Islamic Jurisprudence; Abdur Rahman I. Doi, Sharī'ah: The Islamic Law (London: Ta Ha Publishers, 1984).

21 Omar Qureshi and Aasim I. Padela, "When Must a Patient Seek Healthcare? Bringing the Perspectives of Islamic Jurists and Clinicians into Dialogue," Zygon 51, no. 3 (2016). https://doi.org/10.1111/zygo.12273; Mohammed Ghaly, Islam and Disability: Perspectives in Theology and Jurisprudence (Abingdon, UK: Routledge, 2010).

22 Qureshi and Padela, "When Must a Patient Seek Healthcare?"

23 Abdulaziz Abdulhussein Sachedina, Islamic Biomedical Ethics: Principles and Application (Oxford and New York: Oxford University Press, 2009), 13, www. loc.gov/catdir/toc/ecip0821/2008028322.html. 
24 Raymond De Vries and L. Rott, "Bioethics as Missionary Work: The Export of Western Ethics to Developing Countries," in Bioethics around the Globe, ed. C. Myser (New York: Oxford University Press, 2011).

25 MehrunishaSuleman, "BiomedicalResearchEthics in the Islamic Context:Reflections on and Challenges for Islamic Bioethics," Islamic Bioethics: Current Issues and Challenges, ed. Alireza Bagheri, et al. (Singapore: World Scientific, 2017), 197-228.

26 Aisha Y. Malik, "Physician-Researchers' Experiences of the Consent Process in the Sociocultural Context of a Developing Country," AJOB Primary Research 2, no. 3 (2011); Farhat Moazam, "Families, Patients, and Physicians in Medical Decisionmaking: A Pakistani Perspective," Hastings Center Report 30, no. 6 (2000).

27 Aasim I. Padela, et al., "[Re]considering Respect for Persons in a Globalizing World," Developing World Bioethics (2014), 6. https://doi.org/10.1111/ dewb.12045.

28 Malik, "Physician-Researchers' Experiences of the Consent Process"; Padela et al., "[Re]considering Respect for Persons in a Globalizing World."

29 "Fard al-Kifayah," in The Oxford Dictionary of Islam, ed. John L. Esposito (Oxford: Oxford University Press, 2003), www.oxfordislamicstudies.com/ article/opr/t125/e625\#.

30 Catriona Mackenzie and Natalie Stoljar, Relational Autonomy: Feminist Perspectives on Automony, Agency, and the Social Self (Oxford: Oxford University Press on Demand, 2000); Anita Ho, "Relational Autonomy or Undue Pressure? Family's Role in Medical Decision-Making," Scandinavian Journal of Caring Sciences 22, no. 1 (2008).

31 Padela et al., "[Re]considering Respect for Persons in a Globalizing World"; Malik, "Physician-Researchers' Experiences of the Consent Process."

32 Geert Hofstede, Cultures and Organizations Software of the Mind (New York: McGraw-Hill, 2005), 78; Pablo Rodriguez Del Pozo and Joseph J. Fins, "Islam and Informed Consent: Notes from Doha," Cambridge Quarterly of Healthcare Ethics 17, no. 3 (2008).

33 Pozo and Fins, "Islam and Informed Consent: Notes from Doha."

34 Ibid.

35 Ibid.

36 Ibid.

37 Suleman, "Biomedical Research Ethics in the Islamic Context."

38 Alahmad, Al-Jumah, and Dierickx, "Review of National Research Ethics."

39 Aceil Al-Khatib and Michael Kalichman, "Responsible Conduct of Human Subjects Research in Islamic Communities," Science and Engineering Ethics 25, no. 2 (2017): 463-476.

40 Abbas Rattani and Adnan A. Hyder, "Developing an Islamic Research Ethics Framework," Journal of Religion and Health 58 (2019): 74-86. https://doi.org/ 10.1007/s10943-017-0508-8; Mehrunisha Suleman, "Contributions and Ambiguities in Islamic Research Ethics and Research Conducted in Muslim Contexts: A Thematic Review of the Literature," Journal of Health \& Culture 1, no. 1 (2016).

41 Suleman, "Contributions and Ambiguities in Islamic Research Ethics." 